\title{
SOBRE O DE MAGISTRO, DE SANTO AGOSTINHO
}

João Azevedo ABREU ${ }^{1}$

- RESUMO: Este artigo está dividido em duas partes. Primeiro, mostramos os diferentes papéis das citações presentes no De Magistro, de Santo Agostinho. Depois, comparamos a estrutura em que o texto está disposto com a teoria que é aí desenvolvida. A partir de tal comparação, podemos ver que, nesse texto, uma teoria da linguagem não é filosoficamente fundamental e que o diálogo não é a melhor forma de alcançar a verdade.

- PALAVRAS-CHAVE: Filosofia medieval; filosofia da linguagem; diálogo; aprendizado; ensinamento.

O texto De Magistro, obra agostiniana de 389, é constituído basicamente por um diálogo cujos "personagens" são Agostinho e Adeodato. Pretendemos apresentar neste trabalho algumas observações sobre as citações presentes nesse texto e uma pequena análise de como o conteúdo e a forma do diálogo estão relacionados. Um entendimento mais preciso desta proposta talvez seja possível apenas na medida em que estiver sendo levada a cabo. Por isso, trataremos logo de colocar o leitor diante do trabalho propriamente dito.

Mas, antes, vejamos qual é a teoria geral apresentada ao longo dos capítulos do De Magistro, segundo um arrolamento dos principais tópicos que, grosso modo, constituem o conteúdo do diálogo.

No Capítulo I, ${ }^{2}$ Adeodato e Agostinho concordam que, quando se fala, pretende-se ensinar ou recordar.

1 Bacharel em Filosofia pela Unicamp.

2 As referências ao texto serão feitas pelo número dos capítulos, a fim de que o leitor que não disponha da edição em que nos baseamos possa acompanhar a discussão. 
Enquanto pensamos as palavras, também estamos falando mentalmente.

Além disso, a memória, ao agitar as palavras, traz à mente as coisas das quais as palavras são sinais.

Palavras são sempre sinais e, conforme o Capítulo II, um sinal não pode ser sinal sem significar algo. Por isso, suspende-se a questão do significado da palavra nihil ("nada", em latim) em vista de sua dificuldade.

É já neste capítulo que Agostinho pede a Adeodato que não explique uma palavra por meio de outras, mas que mostre as coisas das quais as palavras são sinais.

Porém é no Capítulo III que se afirma que uma palavra só pode ser explicada por outras palavras, mas aquilo de que uma palavra é sinal pode ser demonstrado por meio de sinais que não são palavras. Se alguém nos pergunta o que é uma coisa e se já estamos fazendo essa coisa, é preciso que utilizemos um sinal para que a pessoa saiba que lhe estamos respondendo. Mas se não estamos fazendo ainda essa coisa, só é preciso fazê-la para mostrar o que ela seja.

Aceitando o último tópico do Capítulo III, temos, no IV: as coisas que são sinais podem ser mostradas por meio de outros sinais. Mas as coisas que não são sinais podem se mostrar ou com gestos ou com algum sinal.

Uma vez que palavra é tudo aquilo que é proferido com a voz e que tem algum significado, o nome também é palavra.

Quando dizemos "verbum" (palavra), queremos também significar um nome. Portanto, a palavra é um sinal do nome.

Todo nome é palavra, mas nem toda palavra é nome.

Há sinais que significam não só outras coisas mas também a si mesmos. Por exemplo, as palavras "verbum" (palavra) e "nome".

De acordo com os capítulos V e VI, "nome" e "palavra" são sinais recíprocos, pois quando dizemos "nome" e "palavra", estamos dizendo dois nomes, mas, também, duas palavras.

Não só os nomes são nomes mas também quaisquer outras palavras o são, porque mesmo as conjunções e os verbos são nomes na medida em que nomeiam algo. Assim, todo nome é palavra e, toda palavra, nome.

No resumo de Adeodato, que forma o Capítulo VII, sistematizando que, dos sinais que se significam reciprocamente, alguns não têm o mesmo valor (como sinal e palavra - aquele abarca mais coisas do que esta), outros têm o mesmo valor (nome e palavra) e outros são idênticos (o termo grego "ónoma" e o latino "nomen").

De acordo com o Capítulo VIII, "homem", como signo, é nome; como coisa significada, animal racional, mortal. Um homem qualquer, então, não é "homem", se por esta palavra entendemos meramente o signo.

Vemos no Capítulo IX que, embora as coisas que existem graças a outras coisas sejam necessariamente de valor menor que as coisas pelas quais outras existem, nem sempre um sinal é de valor menor que o da coisa significada, por exemplo, "coenum" (lamaçal). Mas, conforme a regra, o conhecimento do lamaçal, pelo qual o signo existe, é superior ao próprio signo. 
Adeodato volta atrás, no Capítulo X, acerca do mostrar coisas com sinais. Depois de uma contestação de Agostinho, conclui-se que nada se pode ensinar sem sinais. Em tal momento, encerra-se o diálogo propriamente dito e Agostinho passa a discorrer sozinho.

Depois de constatar que a inteligência do interlocutor pode ser suficiente para que lhe mostremos sem sinal algumas coisas, Agostinho afirma que lhe "vem à mente" que há muitas coisas que podem ser mostradas sem sinal - por exemplo, Deus e todas as coisas da natureza, que se mostram por si mesmas.

Aprende-se não pela palavra, mas pelo significado, que se dá apenas depois que se tem a percepção da coisa. A palavra, por si só, apenas nos desperta para que procuremos as coisas.

No Capítulo XI, podemos ver que, se sabemos o significado de uma palavra, não é porque ela no-lo ensinou, ela apenas o recorda a nós. Se não o sabemos, apenas somos incitados pela palavra a procurá-lo.

Se Isaías disse "se não crerdes, não entendereis", é porque há uma diferença entre crer e entender.

Quando compreendemos uma coisa, não é por meio das palavras que o fazemos, mas pela verdade ensinada por Cristo, a qual se revela mais ou menos ao homem conforme a sua boa ou má vontade.

Agostinho continua, no Capítulo XII: "Cristo é a verdade que ensina interiormente".

Não é a palavra que nos ensina algo, mas os sentidos do corpo (quanto às coisas sensíveis) ou a mente (quanto às coisas inteligíveis).

Quem, a respeito das coisas inteligiveis, muda de opinião à medida que é interrogado e argüido, fá-lo porque "não pode consultar sobre todas as coisas a sua luz interior".

No Capítulo XIII, lê-se que, ainda com respeito às coisas inteligíveis, não cabe às palavras nem sequer manifestar o pensamento de quem fala, haja vista que as palavras de quem fala a verdade que conhece podem ser iguais às daquele que fala algo do que não sabe se é ou não verdade ou também às daquele que mente.

Também com respeito às coisas inteligíveis, o Capítulo XIV mostra que ainda que possa ocorrer que aquele que ouve, ao conhecer já as coisas que ouve, pense que aquele que fala tenha pensado no seu significado, nem por isso se terá obtido a verdade por aprendizado.

O discípulo aprende quando reflete, segundo sua vontade interior, sobre as palavras do mestre, e não assim que o mestre professa sua disciplina.

Quando essa reflexão é simultânea à exposição do mestre, pensa-se que se aprendeu pelo mestre. Mas o mestre é um mero admoestador.

Só há um Mestre: o que está no céu.

A vida bem-aventurada é amar e conhecer a Deus, e isto não é possível pelo mundo exterior. 
Ainda antes de analisarmos a estrutura do diálogo, cabem aqui algumas observações acerca da utilização que Agostinho faz das citações de alguns autores e, principalmente, de passagens da Bíblia. A nossa idéia é a de que as citações nem sempre são meramente ilustrativas - elas têm um papel por vezes fundamental para o encadeamento argumentativo do debate.

Na passagem em que, no Capítulo V, o apóstolo Paulo é citado (trecho extraído de II Coríntios 1, 19), "Não havia em Cristo o sim e o não, mas somente havia nele 0 sim", há apenas a utilização de um recurso, por parte de Agostinho, para mostrar a Adeodato que tanto os "nomes" gramaticais quanto as conjunções e os verbos (como o "est", traduzido do latim por "sim") são todos nomes, na medida em que nomeiam algo. No caso, o recurso é tão persuasivo que Adeodato acaba não só aceitando o argumento de apelo à autoridade de São Paulo, mas também acaba pedindo mais autoridades: "rogo-te que procures algum daqueles em quem se reconhece máxima autoridade na arte da palavra, para demonstrar o que desejas" (Capítulo V, p.303).

Há, no Capítulo IX, uma citação de Pérsio: "Sed stupet hic vitio" ("Mas este se admira do vício") (a partir da Sátira, III, 32), a qual, depois de utilizada por Agostinho na explicação de que o conhecimento do nome do vício é muito inferior ao conhecimento do vício, serve para que Adeodato, reutilizando o nome de Pérsio, afirme, a fim de contestar o que o interlocutor acabara de dizer:

O próprio Pérsio, pois a todas as penas que a crueldade dos tiranos excogitou ou a cabeça fez sofrer, antepõe unicamente aquela com que são atormentados os homens, quando obrigados a reconhecerem os vícios que não conseguem evitar. (Capitulo IX, p.314)

A citação (Capítulo XI, p.319) de Isaías, que se faz presente também no famoso Sermão 43, do próprio Agostinho, funciona aqui como argumento. Assim, segundo Agostinho, se não houvesse diferença entre crença e conhecimento, Isaías não teria dito "Se não crerdes, não entendereis" (Isaías 7, 9).

Por fim, há aquela que talvez seja a citação mais importante do De Magistro, a que fecha a última e longa fala de Agostinho, e que, como veremos a serguir, explica muito da estrutura do diálogo como um todo. Diz Agostinho:

não lhes atribuas [às palavras] importância maior do que é necessário, para que não apenas se creia, mas também se comece a compreender com quanta verdade está escrito nos livros sagrados que não se chame a ninguém de mestre na terra, pois o verdadeiro e único Mestre de todos está no céu.

A referência, implícita aí no Capítulo XIV, é a Mateus 23, 8-10.

Outro recurso discursivo de que Agostinho lança mão é o uso das palavras presentes na linguagem comum. Se é que se pode falar num esboço de filosofia da linguagem nos primeiros capítulos do De Magistro (na verdade, entre outras coisas, 
Agostinho dirá, no último capítulo, que "sobre a utilidade das palavras ... falaremos ... em outra parte" (Capítulo XIV), e não no presente diálogo), o tipo de recurso ao discurso comum nos "remete" à filosofia da linguagem dos últimos séculos e, a partir disso, note-se que, ao menos desde a semiótica de Peirce (1839-1914), não só palavras e gestos são tomados como signos, como também o devem ser as ações, como o caminhar, o escrever etc., as quais Adeodato e Agostinho consideram não sendo sinais (no início - capítulos III e IV do De Magistro - tal distinção chega a constituir prova de que há coisas que podem ser mostradas sem signos, ponto de vista que vai ser alterado no decorrer do diálogo).

A linguagem, em seu sentido corriqueiro, é utilizada para exemplificar a teoria, como quando Agostinho, dizendo que a palavra se refere à percussão do ouvido, enquanto o nome remete ao conhecimento do espírito, complementa: "por isso dizemos muito bem, quando falamos qual é o 'nome' desta coisa desejando gravá-la na memória e não dizemos, ao contrário, 'palavra'"' (Capítulo VIII, p.308).

$\mathrm{E}$, tal como alguns filósofos analíticos do século XX, o senso comum, por outro lado, é, em Agostinho, alvo dos ataques da teoria: argumentando que tanto o ato de apontar o dedo quanto o de dizer "ecce" (eis) nada mais são do que o ato de indicar as coisas, Agostinho critica: "e costumamos acompanhar este advérbio também com o dedo apontado, como se não bastasse um só desses dois sinais para indicar" (Capítulo X, p.318).

\section{3}

Vejamos agora como se estrutura o diálogo De Magistro. São duas grandes partes. A primeira, que constitui um diálogo propriamente dito, se estende do início do texto a té a metade do Capítulo X. A segunda, que compreende desde a segunda metade do Capítulo X até o final do diálogo, é praticamente um monólogo de Agostinho.

Há, na primeira parte, uma coincidência entre a forma do texto e a teoria que aí se procura desenvolver. Mais exatamente, o fato de esta primeira parte constituir um diálogo tem sua razão de ser até mesmo na concepção que os dois "personagens" em questão têm da função da fala. Já no primeiro capítulo, o que se destaca é que o falar tem como finalidade ensinar ou recordar.

Quanto à finalidade de ensinar, as falas da primeira parte vão levando-a mesmo a cabo. Pode-se dizer que tanto Agostinho quanto Adeodato procuram ensinar e aprender ao longo do mútuo inquirir. De fato, Agostinho pode ser considerado o "condutor" do diálogo. São quase sempre suas as hipóteses que vão orientando o debate. Mas não se pode negar que ele também "aprenda" algo. Pode-se perceber isto logo no início do Capítulo VIII, quando Agostinho "confessa" que a organização e síntese que Adeodato executara no capítulo anterior fez que as idéias que haviam sido debatidas ficassem mais claras para ele, Agostinho. Mais um exemplo disso aparece 
na segunda fala de Agostinho no Capítulo IX, quando extrai a conclusão de que nem todas as coisas têm valor superior aos seus sinais a partir de uma reflexão de Adeodato, a qual consistiu em mostrar que não se atribui à palavra "coenum" (lamaçal) o mesmo ódio que à coisa que ela designa. Essa reflexão de Adeodato se antepunha por sua vez à primeira fala de Agostinho no capítulo em questão.

Já o cumprimento, por parte das falas do diálogo, da finalidade de recordar pode ser visto em dois exemplos. O primeiro é constituído pelas passagens bíblicas às quais já nos referimos. Correspondendo ao segundo exemplo, há um capítulo inteiro, o VII, que é uma síntese feita por Adeodato dos seis capítulos anteriores. Em ambos os casos, temos não meras recordações mas, como já vimos, passagens muito importantes para o desenrolar do diálogo. De um lado, as passagens (da Bíblia e de outros autores) que servem até mesmo como recursos argumentativos. De outro, a recapitulação do Capítulo VII, responsável por um dos momentos em que o próprio Agostinho se confessa mais bem esclarecido.

O caráter dialógico dessa primeira parte não compreende uma exposição, vamos dizer assim, doutrinária, por parte de um dos debatedores ao outro. E isto se dá não só porque cada um dos dois personagens tem papel ativo na construção da teoria, como vimos há dois parágrafos, mas também exatamente porque o que há aí é uma tal construção de teoria. Há como que uma "ordem das razões", em razão da qual, por exemplo, algumas questões duvidosas vão sendo deixadas de lado em certos momentos do debate, por não serem passíveis de resolução de acordo com os dados já então assegurados. Tal é o caso da palavra nihil, presente numa citação da Eneida, de Virgílio, no início do Capítulo II. Ainda neste mesmo capítulo, o problema da definição do significado dessa palavra, por sua grande dificuldade, é deixado de lado e vai permanecer sem solução no diálogo como um todo, mesmo porque a segunda parte do texto muda em muito, como veremos, o rumo da discussão. Isto também acontecerá com o que se diz no Capítulo IX, quando se deixa em suspenso se o conhecimento do sinal é superior ao conhecimento da coisa, uma vez que, por um lado, o conhecimento do sinal "vício" é melhor do que conhecer o vício, mas, por outro, o conhecimento do sinal "virtude" não pode ser tomado como melhor do que conhecer a virtude.

Outro aspecto que ressalta o caráter dialógico dessa parte do texto é que chega a acontecer de um ponto, que é duvidoso para um dos debatedores, ser aceito por este mesmo debatedor, a fim de que a discussão possa prosseguir. Um exemplo disso se tem no Capítulo IX, quando Adeodato, mesmo duvidando que tudo o que existe graças a uma outra coisa seja inferior àquilo pelo qual existe, "suspende" a dúvida e permite que Agostinho continue construindo a sua análise.

Mas há uma demonstração ainda maior do fato de essa parte do texto ser formada essencialmente por um diálogo - o que será importante para a compreensão do lugar que esta mesma parte ocupa no texto como um todo. E tal demonstração se tem quando os personagens chegam a mudar uma opinião que até então ambos os debatedores haviam tomado como certa. Próximo à metade do Capítulo X, quando 
o diálogo propriamente dito está quase por terminar, Agostinho conclui, com o mesmo endosso de Adeodato, e depois de alguma reflexão, que nada se pode ensinar sem sinais. A té então, era de opinião comum que havia um certo tipo de ação que poderia ser mostrado sem sinais.

Há, além daquela, uma nova mudança dessa opinião sobre a possibilidade ou não da demonstração de algo sem o uso de sinais, mudança que marca a transição desse diálogo de fato para a parte mais monológica. É a partir da afirmação de que o mostrar algo não depende tanto de como se quer mostrar esse algo, quanto da inteligência daquele a quem se mostra a coisa, afirmação presente nos últimos momentos em que se intercalam as falas de Agostinho e Adeodato; é a partir disso, dizíamos, que Agostinho expõe toda uma teoria em que opõe o conhecimento por palavras ao conhecimento por intermédio do mestre interior; teoria essa que não só altera a maneira como se pode ver a primeira parte do texto, como também, de certo modo, põe em questão a própria razão de ser daquele diálogo inicial.

O saldo final que essa parte monológica do texto nos deixa, mais do que uma reformulação de uma teoria dos sinais cuja tentativa inicial acabara se revelando um tanto inconseqüente, é uma posição crítica em relação ao papel da palavra ou, melhor dizendo, uma teoria da impotência da palavra. Mesmo reconhecendo que a palavra tem sua importância, o De Magistro não é o espaço para se tratar disso. Ao assim afirmar no final de sua exposição, já no Capítulo XIV, Agostinho acaba mostrando que uma teoria propriamente dita da linguagem não é o que se tem no saldo final.

O texto culmina na afirmação da linguagem como insuficiente para expressar as verdades das coisas, uma vez que, segundo sobretudo os Capítulos XIII e XIV, a respeito das coisas inteligíveis, sempre que se pensa que se está aprendendo algo por intermédio das palavras de um outro, na verdade o que se está fazendo é analisar com a sua verdade interior e reconhecendo em si a opinião em questão, para a formação da qual a verdade não foi aprendida, mas já estava presente interiormente naquele que se acha "aprendendo" e foi, no máximo, suscitada pelas palavras daquele que se acha "ensinando".

Diante disso tudo, com que olhos se pode ler aquela primeira parte do texto ou, colocando a questão de maneira mais brusca, para que serviu toda aquela tentativa de formulação de uma teoria dos sinais?

Não é difícil ver, em algumas das falas de Agostinho, alguns indícios de como interpretar aquele diálogo. E esses indícios acabam, diretamente ou não, corroborando a idéia de impossibilidade de fazer-se um diálogo propriamente dito, como se queria no início, sobre as coisas inteligíveis.

No Capítulo X, pouco antes de iniciar a sua longa exposição, Agostinho já lembra o pouco rendimento que obtiveram ele e Adeodato depois da longa discussão anterior sobre os sinais. Até então, apenas três questões haviam sido resolvidas. Aqui, trata-se de uma crítica, ainda não de todo contundente, em direção a esse diálogo em particular.

Já em meados do Capítulo XII, Agostinho diz que aquele que vai mudando de opinião e aceitando as alheias, à medida que é questionado e argüido num diálogo como 
aquele, na verdade não está consultando a sua verdade interior sobre as coisas. Aí, a crítica se estende a uma forma como se podem comportar os debatedores num diálogo, como tal havia sido o comportamento de Agostinho e Adeodato ao longo da discussão sobre os sinais. A crítica atinge o próprio diálogo por eles até então efetuado.

Por fim, há a crítica aos diálogos em geral, presente numa das principais teses do último discurso de Agostinho: não é num diálogo que se pode aprender algo sobre as coisas inteligíveis, dado que estas não se aprendem mesmo em lugar nenhum.

Ou seja, nessa "crítica ao diálogo", pode-se ver que a função da parte dialógica inicial seria a de mostrar, por meio de um diálogo mesmo sobre coisas inteligíveis, os problemas de um tal diálogo. Aliás, Adeodato e Agostinho, como já vimos, mais de uma vez se queixam da insegurança com que conduzem a discussão. É que o diálogo, como também vimos há pouco, não leva necessariamente à busca, por parte da verdade interior, do que sejam as coisas.

Mas, além do problema da razão de ser do diálogo inicial, aparece uma outra questão: qual a importância de a forma daquele mesmo diálogo estar tão relacionada com o seu conteúdo, como procuramos demonstrar neste nosso trabalho?

A resposta pode ser extraída de um confronto entre as conclusões do Capítulo XIV e as do diálogo inicial. No último capítulo, podem-se entender, também, a razão do título do diálogo, De Magistro, e a razão da divisão do texto nesses dois grandes blocos.

Como não se ensina por palavras sobre as coisas inteligíveis, não existem os chamados mestres, a não ser o Mestre do céu, que ensina interiormente. Não há então como ir muito longe se se pretende, como naquele diálogo do início, ensinar algo sobre as coisas inteligiveis, a não ser no sentido de que as palavras de um dos debatedores podem servir para despertar o outro para que busque em si mesmo uma verdade interior.

Não para isto que acabamos de dizer, mas apenas para suscitar esta verdade, bastaria, como Agostinho parece esperar (ao final do Capítulo XIV), uma exposição não dialógica como a que faz ao final do texto. O que acontece entre os dois blocos é que Agostinho "de repente" interrompe o diálogo, como que apercebendo-se de que um discurso seria mais eficiente para falar daquilo que possa ser ensinar algo. É como se ele próprio tivesse tido sua verdade interior desperta (como vimos na análise da forma do diálogo inicial, Agostinho também estava na condição de aprendiz) pelas palavras do diálogo e resolvido fazer, da maneira menos desgastante, que Adeodato compartilhasse desse despertar.

Em virtude do último capítulo do De Magistro, também fica estabelecido, a propósito da primeira parte do texto, que já estava errado o próprio ponto de partida daquele diálogo inicial, ou seja, o de que a função do falar é o ensinar. Como se vê ao final do texto, palavras não ensinam. Mas talvez se pudesse pensar que Agostinho deu seqüência ao tal diálogo apenas em razão da primeira resposta de Adeodato (de certo modo, é do interlocutor de Agostinho o ponto de partida teórico da primeira etapa...) e levou em frente o debate a fim de mostrar, mesmo num diálogo, que aquela 
resposta estava errada. Mas por que faria isso, sabendo que as palavras de um diálogo não levariam Adeodato a aprender alguma coisa? Talvez Agostinho esperasse que as palavras do diálogo suscitassem a verdade interior em Adeodato, mas tenha visto que, em razão do pouco sucesso do diálogo, seria melhor fazer, como de fato fez, um longo discurso sobre a "inutilidade das palavras". Ou, talvez, o próprio Agostinho só tivesse despertado a sua verdade interior no meio do Capítulo X e, aí, resolvido monologar. Mas tudo isso não passa de suposições...

O que há para enfatizar ainda é que a última fala de Agostinho não poderia mesmo ser um diálogo, em coerência com o que diz a teoria presente nessa fala. Se não se pode esperar que o ouvinte de uma exposição tenha aprendido algo a partir dela, mas sim que tenha sido motivado por ela a pensar por si só sobre os mesmos assuntos, por que Agostinho esperaria um diálogo filosófico acerca disso com Adeodato? Agostinho, de fato, ainda inquire Adeodato ao final de sua fala, mas já não o faz filosoficamente, pois, como se vê aí mesmo, já até sabe explicar a resposta de Adeodato, qualquer que ela venha a ser: se Adeodato concordar com o que já foi dito, não o fará porque Agostinho lhe ensinou; se não concordar, será porque ainda não tem a possibilidade de aprender.

ABREU, J. A. Concerning Saint Augustine's De Magistro. Trans/Form/Ação (São Paulo), v.19, p.211-219, 1996.

- ABSTRACT: This paper is divided in two parts. At first, we show the different roles played by quotations all through Saint Augustin's De Magistro. We compare then the structure in which the text is established to the theory that is developed over there. From such a comparison, we can see that in the mentioned text a theory of language isn't philosophically fundamental and that a dialogue isn't the best way to reach the truth.

- KEYWORDS: Medieval philosophy; philosophy of language; dialogue; learning; teaching.

\section{Referências bibliográficas}

SANTO AGOSTINHO. De Magistro. In: Confissões; De magistro. Trad. A. Ricci.

São Paulo: Nova Cultural, 1987. 